\title{
An Elevated High-Density Lipoprotein Cholesterol Levels Is Associated with Favorable Outcomes of Patients with Small-Artery Occlusion
}

Hao Ruixiao

Tianjin Medical University

Liu Peipei

Tianjin Medical University

Wang Yajing

Tianjin Huanhu Hospital

Jialing Wu ( $\nabla$ wywjl2009@hotmail.com )

Tianjin Huanhu Hospital

\section{Research Article}

Keywords: High-Density Lipoprotein Cholesterol, Stroke, Outcome, Small-Artery Occlusion

Posted Date: March 6th, 2019

DOI: https://doi.org/10.21203/rs.2.294/v1

License: (a) (i) This work is licensed under a Creative Commons Attribution 4.0 International License. Read Full License 


\section{Abstract}

Background: The relationship between high-density lipoprotein (HDL) cholesterol and small-artery occlusion (SAO) is not well understood.

Methods: A total of 3067 consecutive patients with SAO were recruited from Tianjin Huanhu Hospital between January 01, 2008, and December 31, 2015. HDL values at admission were classified into four groups according to quartiles $(<0.92,0.92-1.08,1.08-1.28$, and $\geq 1.28)$. Patients were followed up to 12 months after stroke. Prognoses, represented by modified Rankin scale (mRS), were estimated via HDL quartiles upon admission utilizing multivariate logistic regression analysis. Meanwhile, we conducted additional subgroup analyses to investigate associations according to age.

Results: Among 3067 patients, 2284(74.5\%) were classified as having favorable outcomes, 783(25.5\%) had a composite of poor outcomes,recurrent stroke, myocardial infarction or vascular death within 12 months. After adjustment for possible confounders, HDL levels in the two highest quartiles (1.08-1.28 and $\geq 1.28)$ were correlated with the 12 -month primary outcome of patients with SAO $(1.08-1.28,0.587$; $95 \% \mathrm{Cl}, 0.394-0.873 ; \mathrm{P}=0.009 ; \geq 1.28,0.448 ; 95 \% \mathrm{Cl}, 0.291-0.688 ; \mathrm{P}<0.001)$. However, a direct correlation was found in patients aged $45-75$ years $(1.08-1.28, P=0.033 ; \geq 1.28, P=0.001)$. Similar to the primary outcome,a direct correlation was also found in patients aged $45-75$ years with a 12-month secondary outcomes $(\geq 1.28 \mathrm{mmol} / \mathrm{L}, \mathrm{p}=0.001)$.

Conclusions: An elevated HDL cholesterol level in patients with SAO is an independent predictor of a favorable prognosis 12 months after SAO. However, the association was only present in patients aged 45-75 years.

Keywords: High-Density Lipoprotein Cholesterol, Stroke, Outcome, Small-Artery Occlusion.

\section{Background}

Stroke is a disease with high mortality and incidence rates worldwide; thus, it is an important health topic and is associated with an increased global economic burden [1,2]. Ischemic stroke events account for $71 \%$ of global stroke cases, and are classified into five subtypes according to the Trial of Org 10172 in Acute Stroke Treatment (TOAST) [3,4]. Small-artery occlusion (SAO), one subtype caused by the occlusion of the branches of small penetrating arteries, accounts for $25 \%$ of ischemic stroke cases [5]. Despite its association with lower mortality and disability rates, the prevalence and progression of SAO is associated with motor dysfunction, including falls, as well as progressive cognitive decline, vascular dementia, and vascular parkinsonism. Furthermore, cerebral small vessel diseases such as SAO present a risk that can impair the quality of life. [6-8]. Although the pathophysiology of SAO is not clear, it is crucial to identify risk factors and explore ways to improve the quality of life for patients and reduce stroke burden $[5,9]$.

Several studies have identified risk factors strongly associated with SAO prognoses including irregular glucose metabolism, fibrinogen abnormalities, and lipid metabolism disorders $[7,10,11,12]$. In particular, 
studies evaluated the role of dyslipidemia factors, including elevated low density lipoprotein (LDL) cholesterol, triglycerides (TG), total cholesterol (TC), and decreased high-density lipoprotein (HDL) cholesterol. A strong correlation between LDL cholesterol level, coronary heart disease, and stroke has been demonstrated by numerous studies [11-13]. While reports have revealed that TG and TC levels are associated with lacunar infarction $[14,15,16]$, there have been few investigations evaluating HDL cholesterol levels that can predict ischemic stroke; moreover, the outcomes are inconsistent. It is imperative to clarify this association and provide appropriate clinical guidance. The aim of this study was to investigate the association between HDL levels and SAO prognoses in patients with stroke categorized by age.

\section{Methods}

Study population

Consecutive patients with stroke were chosen from a hospital-based registry established in Tianjin Huanhu Hospital, a specialized neurology hospital in Tianjin, China. We reviewed and extracted detailed information on patients from the registry between January 01, 2008, and December 31, 2015. Patients who had their first ischemic stroke event within 7 days of onset and whose medical history, behavioral factors, family history, neurological examination, standard 12-lead echocardiography, standardized blood tests, and imaging (magnetic resonance imaging or computed tomography) results led to a subsequent SAO diagnosis were included in our study; in addition, our inclusion criteria also required HDL values to be provided upon admission. Patients with a stroke classification of atherothrombotic, cardioembolic, and other or undetermined causes according to TOAST criteria were excluded from our analysis. Other exclusion factor included no data on lipids and lack of follow-up.

Among the 17,980 patients diagnosed with ischemic stroke according to World Health Organization criteria [17], 3483 were diagnosed with SAO upon admission; thus, the 14,497 patients with non-SAO strokes were excluded from our study. After excluding patients that did not have HDL data on blood lipids collected upon admission,missing follow-up reports or other reasons, 3067 patients with SAO remained that met all the inclusion criteria and were analyzed in the present study (Figure 1). Patients were classified into three subgroups according to age ( $<45$ years, $n=140 ; \geq 45$ and $<75$ years, $n=2054 ; \geq 75$ years, $n=312$ ).

Patients were evaluated for SAO by two experienced neurologists. SAO cases categorized as lacunar infarcts using other classification systems [18] were diagnosed based on the following criteria: The patient exhibited one of the traditional clinical lacunar syndromes without evidence of cerebral cortical dysfunction. Patients also had a relevant brain stem or subcortical hemispheric lesion $<1.5 \mathrm{~cm}$ in diameter detected via computed tomography or magnetic resonance imaging. Additionally, no potential cardiac sources for embolism were present and stenosis was less than $50 \%$ in an ipsilateral artery. A history of diabetes mellitus or hypertension further supported the clinical diagnosis. All patients included in present study were diagnosed with Small-artery occlusion,those with a poor prognosis for survival (loss 
of consciousness or severe comorbidities), those with preexisting disabilities of the extremities were excluded from this study.

Demographic and clinical assessment

Baseline information and stroke risk factors were obtained from a record of clinical history within 24 hours of admission; information included age, sex, medical history, and detailed demographic data. Biochemical variables in the blood were measured following a fasting period of at least eight hours on the first day after admission and were analyzed in a certified central laboratory.

$\mathrm{HDL}$ values were classified into four quartiles $(<0.92,0.92-1.08,1.08-1.28 \llbracket$ and $\geq 1.28 \mathrm{mmol} / \mathrm{L})$, since quartile classification is the most common statistical layering method. Hypertension was documented for patients with a systolic blood pressure $\geq 140 \mathrm{mmHg}$ and/or diastolic blood pressure $\geq 90 \mathrm{mmHg}$ on the seventh day after stroke onset, systolic and diastolic blood pressures of 140/90 $\mathrm{mmHg}$, and for patients taking antihypertensive medications [15]. Diabetes mellitus was identified in patients with fasting blood glucose levels $\geq 7.0 \mathrm{mmol} / \mathrm{L}$, non-fasting glucose levels $\geq 11.1 \mathrm{mmol} / \mathrm{L}$, a previous diagnosis of diabetes, and/or the use of hypoglycemic agents with a glycated hemoglobin ( $\mathrm{HbA} 1 \mathrm{c}$ ) level $\geq 6.5 \%$ at the time of admission $[19,20]$. Dyslipidemia was characterized in patients being treated with cholesterolreducing agents as well as in patients with a TG level $>2.26 \mathrm{mmol} / \mathrm{L}(200 \mathrm{mg} / \mathrm{dL})$ or a TC level $>6.21$ $\mathrm{mmol} / \mathrm{L}(240 \mathrm{mg} / \mathrm{dL})$. Individuals who had smoked tobacco products every day for more than a year were defined as current smokers. Alcohol drinkers were defined as those who consumed alcohol at least once per week for more than 1 year. Body mass index $\left(\mathrm{kg} / \mathrm{m}^{2}\right)$ was calculated at the time of admission, and obesity was defined as a body mass index $\geq 30 \mathrm{~kg} / \mathrm{m}^{2}$ [21]. Stroke severity was assessed using the National Institutes of Health Stroke Scale (NIHSS) [22].

Functional outcome and follow-up

The primary outcome was prognoses of patients with SAO (favorable or poor prognoses) during a 12month period after stroke onset.Secondary outcomes included poor prognoses, and composite of recurrent stroke,myocardial infarction (MI) or vascular death within 12 months. The 12-month follow-up was done by telephone interviews or in-person interviews; all results were recorded into our electronic stroke database immediately to ensure reliability. The modified Rankin scale (mRS) was used to evaluate functional outcomes: mRS scores of $0-2$ represented favorable prognoses and $m R S$ scores of 3-5 indicated poor prognoses.

Statistical analysis

In this study, continuous variables are presented as means \pm standard deviations and categorical variables are reported as counts and proportions. We assessed the significance of intergroup differences using t-tests and one-way analysis of variance tests; chi-squared tests or Fisher's exact tests were used to determine differences between groups. A multiple logistic regression analysis was used to evaluate the relationship between HDL levels and stroke prognoses with mRS scores. Statistical analyses were 
performed using the Statistical Package SPSS 24.0. All tests were two-sided, and $p$ values $<0.05$ were considered statistically significant.

\section{Results}

\section{Baseline demographics and clinical characteristics of study participants}

Table 1 outlines the baseline demographics and clinical characteristics according to the HDL quartiles. The mean HDL level of all patients was $1.126 \pm 0.31 \mathrm{mmol} / \mathrm{L}$ (range, $0.25-6.11 \mathrm{mmol} / \mathrm{L}$ ). NIHSS scores ranged from 0 to 14. In the present study, we collected data on 3067 patients (2134 men [69.6\%]; 933 women $[30.4 \%]$ ). Mean age was $61.94 \pm 11.08$ years. Among them, $29.5 \%$ had diabetes and $64.7 \%$ had hypertension. There was a statistically significant difference among the stratifications regarding HDL levels and lipid metabolism disorders $(p<0.05)$. Patients with HDL levels in the highest quartile were less likely to have diabetes $(n=164,21.2 \%)$ and to smoke $(n=267,34.5 \%)$.

\section{Evaluation of risk factors between groups classified by outcomes}

Table 2 describes the comparison of risk factors between different groups classified by outcomes. Among patients, 2284 (74.5\%) had an favorable outcome. As it shows the following factors to be independently associated with the 12-month primary outcomes: age, HDL levels, and NIHSS scores ( $p<$ $0.001, p=0.006, p<0.001$,respectively).Younger patients $(60.87 \pm 10.82)$ had more favorable outcomes than older patients $(64.23 \pm 11.00)$. However, there were no significant associations with other risk factors (sex, hypertension, diabetes, smoking, alcohol consumption, and obesity). In addition,of 3067 patients,783(25.5\%) had a composite of poor outcomes,recurrent stroke, Ml or vascular death within 12 months. Similar to the primary outcome predictors,secondary outcomes were significantly correlated with age, HDL levels, and NIHSS scores(all $p$ values $<0.05$ ). Patiets with favorable outcomes were more likely to be the younger(60.87 \pm 10.82$)$.

\section{Multivariate logistical regression analyses of HDL groups and outcomes}

Table 3 presents the results of the logistic regression analyses of HDL levels and outcome variables. As shown in the table, HDL levels in the two higher quartiles $(1.08-1.28, \geq 1.28)$ were significantly associated with the 12-month primary outcome as compared with the reference of HDL levels in the lowest quartile (adjusted odds ratio, $1.08-1.28,0.587 ; 95 \% \mathrm{Cl}, 0.394-0.873 ; \mathrm{P}=0.009 ; \geq 1.28,0.448 ; 95 \%$ $\mathrm{Cl}, 0.291-0.688 ; \mathrm{P}<0.001)$. Similar to the primary outcome,with 12-month secondary outcomes, patients with HDL levels in the two higher quartiles $(1.08-1.28, \geq 1.28)$ had more favorable outcomes(adjusted odds ratio, $1.08-1.28,0.788 ; 95 \% \mathrm{Cl}, 0.621-0.999 ; \mathrm{P}=0.049 ; \geq 1.28,0.713 ; 95 \% \mathrm{Cl}, 0.560-0.909 ; \mathrm{P}=$ 0.006).Meanwhile, there was a statistically significant association between age and SAO primary and secondary outcome (both $\mathrm{P}$ values $<0.001$ ).

Table 4 further shows the association between HDL levels and outcomes according to age. We found a statistically significant direct correlation for the age range of 45-75 years with the primary outcome of 
stroke(1.08-1.28 mmol $/ \mathrm{L}, \mathrm{p}=0.033 ; \geq 1.28 \mathrm{mmol} / \mathrm{L}, \mathrm{p}=0.001$, respectively).Furthermore,the similar association was found for patients with the secondary outcomes $(\geq 1.28 \mathrm{mmol} / \mathrm{L}, \mathrm{p}=0.001)$. However, no association was found between outcomes and the lower HDL stratification with the age range of 45-75 years, neither the primary outcome $(0.92-1.08 ; p=0.064)$ nor the secondary outcomes $(0.92-1.08 ; p=$ $0.305)$.

\section{Discussion}

The present study analyzed the clinical data of patients with SAO according to different age groups using data obtained from a hospital-based stroke registry from Tianjin, located in northern China. The higher HDL stratification levels $(1.08-1.28, \geq 1.28)$ were strongly correlated with favorable outcomes of patients with SAO; this clear positive association was observed in patients from 45 to 75 years of age.

Our results indicated that elevated HDL cholesterol levels may facilitate a favorable prognosis for patients with SAO. Previous studies have demonstrated that low HDL cholesterol levels were not only associated with the risk of incident stroke, but also with cerebral small vessel disease $[19,23,24,25,26]$. In addition, both the Japan Public Health Center study (2017) and the Holmes (2018) study reported an inverse relationship between HDL cholesterol levels and SAO. Furthermore, the Holmes (2018) study provided evidence demonstrating that cholesterol ester transfer proteins mediated higher HDL cholesterol levels and were associated with a lower risk of SAO, genetically $[19,25,26]$. Our results support these study findings; however, a meta-analysis of randomized controlled trials did not show that raising HDL levels will reduce the risk of stroke, but these results could have been affected by off-target effects of the drugs [27]. Moreover, a Framingham study provided no evidence to support a causal relationship between the role of $47 \mathrm{HDL}$ cholesterol single nucleotide polymorphisms and ischemic stroke [28]; however, compared with the 3067 patients in our study, this previous study only involved 301 participants with ischemic stroke. Differences between our study results and previous studies may be due to patient race, age, and analytic strategies; for instance, the percentage of women was higher in the aforementioned Framingham study, $56 \%$ [28], compared with the $30.4 \%$ of women in our study.

Our analysis revealed an inconsistent association between HDL and stroke similar to previous findings concerning cardiovascular disease [29]. Some randomized controlled trials explored the clinical benefits of elevated HDL cholesterol levels for patients diagnosed with cardiovascular disease by adding niacin to statin therapy. One study showed that elevated HDL levels contributed to the regression of angiographic coronary-artery stenoses [30]; however, another study surprisingly reported no clinical benefits after increasing HDL cholesterol levels for patients with cardiovascular disease and failed to provide evidence for a causal link between extended-release niacin and ischemic stroke [29]. Nevertheless, there are no reported clinical studies analyzing the relationship between elevated HDL levels and ischemic stroke or ischemic stroke subtypes; thus, further evaluation is needed to clarify these contradictory findings. Nevertheless, our results are valid and may be used to provide clinical guidance in northern China. 
Additionally, our previous studies found that hemoglobin A1c levels and high-sensitivity C-reactive proteins (hs-CRPs) were associated with SAO outcomes [10,31]. Although, hyperglycemia and hs-CRPs may be related to endothelial damage and inflammatory responses, thus leading to the occlusion of deep penetrating vessels, dysglycemia may also intensify lipid disorders that can aggravate the inflammatory responses of vessels. Therefore, these risk factors are independent and interrelated, further signifying the importance of evaluating risk factors related to dyslipidemia in clinical practice.

Although there is a significant relationship between $\mathrm{HDL}$ cholesterol and SAO, the underlying mechanism is not clear. HDL plays a key role in promoting reverse cholesterol transport from the periphery to the liver. Furthermore, mounting evidence has demonstrated that the reverse cholesterol transport process may provide protection from atherosclerosis, which can lead to lacunar infarcts through artery occlusion [26,32]; in fact, some studies found impaired carbon dioxide $\left(\mathrm{CO}_{2}\right)$ vasoreactivity in lacunar infarct patients. While serum $\mathrm{HDL}$ cholesterol affects cerebral vasculature $\mathrm{CO}_{2}$ reactivity by increasing the permeability of the blood-brain barrier, the increased permeability may lead to glial and neuronal damage by allowing blood products to diffuse into the perivascular space[26]. Also, some evidence suggests that HDL cholesterol may activate endothelial nitric oxide synthase to promote endothelial repair, induce angiogenesis, and increase platelet reactivity, anti-inflammatory reactions, and hypercoagulability functions[19,33,34]. Furthermore, modulating HDL levels may be implicated in vascular remodeling and functional recovery $[34,35,36]$.

Our study also found that elevated HDL cholesterol levels were associated with favorable prognoses only in patients aged from 45 to 75 years after multivariate adjustment, and this association was presented both in the primary outcome group and the secondary outcomes.Similar to our study,Aleksandra et al found that lower HDL cholesterol levels was significant in middle-aged and elderly persons[23],which may be strongly correlated with the HDL cholesterol's above-mentioned anti-inflammatory and antiatherogenic pathophysiology $\square$ No association was presented between HDL cholesterol levels with SAO outcomes in the oldest-old patients( $\geq 75$ years).That might be associate with a higher risk of comorbidity with increasing age, and multiple risk factors acting together may attenuate the impact of any one independent risk or protective factor,such as the protection of HDL cholesterol.Studies have indicated hypertension, hyperglycemia and dyslipidemia were the major risk factors of small artery occlusion in young adults.Nevertheless, the young people have less complication,higher compensatory function and adjustable life style.Controlling weight and alcohol,quit smoking,exercise and good medication compliance can regulate blood pressure,blood glucose and lipid metabolism, which contribute to favorable outcomes in the young.

The clinical information that was collected for a large number of SAO cases, promptly drawn blood samples, and inclusion of adults of any age enhanced the robustness of our study. Our findings suggest the importance of maintaining HDL cholesterol values in higher stratifications using lipid-regulating drugs or proper exercise for patients with SAO. However, there were several limitations to our study. First, we collected clinical information for SAO cases from one hospital in Tianjin; thus the patient population does not represent the general population of China that may otherwise vary by region, diet, lifestyle, and other 
factors. Furthermore, we did not consider the use of lipid-lowering medications such as statins. The influence of statins on HDL cholesterol values during the follow-up period is unclear and may have affected the outcomes of patients with SAO. In addition, patients without HDL cholesterol data upon at admission were not included in this study, which may have presented a selection bias. Finally, other limitations were those particularly inherent to retrospective studies.

\section{Abbreviations}

$\mathrm{Cl}$, confidence interval;

HbA1c, hemoglobin A1c;

HDL-C, High-Density Lipoprotein Cholesterol;

hs-CRP, High-Sensitivity C-Reactive Protein;

LAA, large-artery atherosclerosis ;

LDL-C, Low-Density Lipoprotein Cholesterol;

mRS, modified Rankin scale;

NIHSS ,National Institutes of Health Stroke Scale;

OR, odds ratio;

SAO, Small-artery occlusion;

TOAST, Trial of ORG10172 in Acute Stroke Treatment;

TC, Total Cholesterol;

TG, Triglycerides

\section{Declarations}

\section{Ethics approval and consent to participate}

The Ethics Committee of Tianjin Huanhu Hospital approved the study protocol. All patients consent to participate in this observational study. Written informed consent was obtained from each participant according to the demand of Local Ethics Committee of Tianjin Huanhu Hospital. A written consent could be obtained directly from the patient. In some circumstances that the patient was unable to sign because of hemiplegia, a written consent could be obtained from a family member. The ethics committee approved this procedure. 


\section{Consent for publication}

Not applicable.

\section{Availability of data and materials}

The datasets analysed during the current study are available from the corresponding author on reasonable request.

\section{Competing interests}

All authors declare that they have no competing interests.

\section{Funding}

This study was generously supported by the National Natural Science Foundation of China (81671169, to J.W), Tianjin Municipal Science and Technology Commission (17JCZDJC36500, to J.W), and Grants from General Administration of Sport of China (2015B098, to J.W). The former two grants supported the design, data collection and analysis of this study, and the latter one supported the interpretation of data and in writing the manuscript.

\section{Authors' contributions}

JW took part in design of the study, funding obtained, interpretation of the data and revising the manuscript. $\mathrm{RH}, \mathrm{PL}$ and $\mathrm{YW}$ carried out the studies, participated in collecting data. $\mathrm{RH}$, and PL drafted the manuscript. $\mathrm{RH}$ and $\mathrm{YW}$ performed the statistical analysis and participated in its design. All authors read and approved the final manuscript.

\section{Acknowledgements}

The authors acknowledge the invaluable participation of the patients.

\section{References}

1. Krishnamurthi RV, Feigin VL, Forouzanfar MH, Mensah GA,Connor M, Bennett DA,Moran AE,Sacco RL, Anderson LM,Truelsen T, O'Donnell M, Venketasubramanian N,Barker-Collo S, Lawes CM, Wang W, Shinohara Y, Witt E,Ezzati M, Naghavi M,Murray C; Global Burden of Diseases,Injuries, Risk Factors Study 2010 (GBD 2010); GBD Stroke Experts Group. Global and regional burden of first-ever ischaemic and haemorrhagic stroke during 1990-2010: findings from the Global Burden of Disease Study 2010. Lancet Glob Health. 2013 Nov;1(5):e259-81.

2. Hata J, Kiyohara Y. Epidemiology of stroke and coronary artery disease in Asia. Circ J. 2013;77(8):1923-32. 
3. Feigin VL, Krishnamurthi RV, Parmar P, Norrving B, Mensah GA, Bennett DA, Barker-Collo S, Moran AE, Sacco RL, Truelsen T, Davis S, Pandian JD, Naghavi M,Forouzanfar MH, Nguyen G, Johnson CO, Vos T, Meretoja A, Murray CJ, Roth GA; GBD 2013 Writing Group; GBD 2013 Stroke Panel Experts Group. Update on the Global Burden of Ischemic and Hemorrhagic Stroke in 1990-2013: The GBD 2013 Study.Neuroepidemiology. 2015;45(3):161-76.

4. 4.Adams HP Jr, Bendixen BH, Kappelle LJ, et al.Classification of subtype of acute ischemic stroke.Definitions for use in a multicenter clinical trial.TOAST. Trial of Org 10172 in Acute Stroke Treatment.Stroke. 1993;24:35-41.

5. Lavallée PC, Labreuche J, Faille D, Huisse MG, Nicaise-Roland P, Dehoux M,Gongora-Rivera F, Jaramillo A, Brenner D, Deplanque D, Klein IF, Touboul PJ,Vicaut E, Ajzenberg N; Lacunar-B.I.C.H.A.T. Investigators. Circulating markers of endothelial dysfunction and platelet activation in patients with severe symptomatic cerebral small vessel disease. Cerebrovasc Dis. 2013;36(2):131-8.

6. Benjamin P, Trippier S, Lawrence AJ, Lambert C, Zeestraten E, Williams OA,Patel B, Morris RG, Barrick TR, MacKinnon AD, Markus HS. Lacunar Infarcts, but Not Perivascular Spaces, Are Predictors of Cognitive Decline in Cerebral Small-Vessel Disease. Stroke. 2018 Mar;49(3):586-593.

7. Staszewski J, Piusińska-Macoch R, Brodacki B, Skrobowska E, Stępień A.Association between hemostatic markers, serum lipid fractions and progression of cerebral small vessel disease: A 2-year follow-up study. Neurol Neurochir Pol.2018 Jan - Feb;52(1):54-63.

8. Steinke W, Ley SC. Lacunar stroke is the major cause of progressive motor deficits. Stroke. 2002 Jun;33(6):1510-6.

9. Feigin VL, Roth GA, Naghavi M, Parmar P, Krishnamurthi R, Chugh S, Mensah GA, Norrving B, Shiue I, Ng M, Estep K, Cercy K, Murray CJL, Forouzanfar MH; Global Burden of Diseases, Injuries and Risk Factors Study 2013 and Stroke Experts Writing Group. Global burden of stroke and risk factors in 188 countries, during 1990-2013: a systematic analysis for the Global Burden of Disease Study 2013.Lancet Neurol. 2016 Aug;15(9):913-924.

10. 10.Gao Y, Jiang L, Wang H, Yu C, Wang W, Liu S, Gao C, Tong X, Wang J, Jin Y, Wu J. Association between Elevated Hemoglobin A1c Levels and the Outcomes of Patients with Small-Artery Occlusion: A Hospital-Based Study. PLoS One. 2016 Aug 3;11(8):e0160223.

11. Bezerra DC, Sharrett AR, Matsushita K, Gottesman RF, Shibata D, Mosley TH Jr, Coresh J, Szklo M, Carvalho MS, Selvin E. Risk factors for lacune subtypes in the Atherosclerosis Risk in Communities (ARIC) Study. Neurology. 2012 Jan 10;78(2):102-8.

12. Chen $\mathrm{Y}$, Hu M, Gong H. Correlation analysis between the LDL-C in serum and the onset of transient ischemic attack caused by CSVD. Exp Ther Med. 2017 Aug;14(2):1119-1125.

13. Imamura T, Doi Y, Arima H, Yonemoto K, Hata J, Kubo M, Tanizaki Y, Ibayashi S,lida M, Kiyohara Y. LDL cholesterol and the development of stroke subtypes and coronary heart disease in a general Japanese population: the Hisayama study.Stroke. 2009 Feb;40(2):382-8.

14. Fukui S, Imazeki R, Amano Y, Kudo Y, Amari K, Yamamoto M, Todoroki K, Ikeya Y,Okazaki T, Yanagimachi N, Shizuma T, Fukuyama N, Johkura K, Mori H. Common and specific risk factors for 
ischemic stroke in elderly: Differences based on type of ischemic stroke and aging. J Neurol Sci. 2017 Sep 15;380:85-91.

15. Shin DW, Lee KB, Seo JY, Kim JS, Roh H, Ahn MY, Lee JS. Association between Hypertriglyceridemia and Lacunar Infarction in Type 2 Diabetes Mellitus. J Stroke Cerebrovasc Dis. 2015 Aug;24(8):18738.

16. Staszewski J, Piusińska-Macoch R, Brodacki B, Skrobowska E, Stępień A.Association between hemostatic markers, serum lipid fractions and progression of cerebral small vessel disease: A 2-year follow-up study. Neurol Neurochir Pol.2018 Jan - Feb;52(1):54-63.

17. WHO Task Force on Stroke and other Cerebrovascular Disorders: Stroke-1989 (1989) Recommendations on stroke prevention, diagnosis, and therapy. Stroke 20: 1407-1431

18. Bamford J, Sandercock P, Jones L, Warlow C: The natural history of lacunar infarction:The Oxfordshire Community Stroke Project.Stroke 1987;18:545-551

19. Saito I, Yamagishi K, Kokubo Y, Yatsuya H, Iso H, Sawada N, Inoue M, Tsugane S.Association of highdensity lipoprotein cholesterol concentration with different types of stroke and coronary heart disease: The Japan Public Health Center-based prospective (JPHC) study. Atherosclerosis. 2017 Oct;265:147-154.

20. American Diabetes Association (2010) Standards of Medical Care in Diabetes? 2010.Diabetes Care 33(Suppl 1): S11-S61.

21. Wilterdink, J. L., Bendixen, B., Adams, H. P. Jr., Woolson, R. F., Clarke, W. R., and Hansen, M. D. (2001). Effect of prior aspirin use on stroke severity in the trial of Org 10172 in acute stroke treatment (TOAST). Stroke 32, 2836-2820.

22. Lyden P, Brott T, Tilley B, et al. Improved reliability of the NIH Stroke Scale using video training. NINDS TPA Stroke Study Group. Stroke 1994;25:2220-6.

23. Pikula A, Beiser AS, Wang J, Himali JJ, Kelly-Hayes M, Kase CS, Yang Q,Seshadri S, Wolf PA. Lipid and lipoprotein measurements and the risk of ischemic vascular events: Framingham Study. Neurology. 2015 Feb 3;84(5):472-9.

24. 24.Lee JS, Chang PY, Zhang Y, Kizer JR, Best LG, Howard BV. Triglyceride and HDL-C Dyslipidemia and Risks of Coronary Heart Disease and Ischemic Stroke by Glycemic Dysregulation Status: The Strong Heart Study. Diabetes Care. 2017 Apr;40(4):529-537.

25. 25. Holmes MV, Millwood IY, Kartsonaki C, Hill MR, Bennett DA, Boxall R, Guo Y, Xu X, Bian Z, Hu R, Walters RG, Chen J, Ala-Korpela M, Parish S, Clarke RJ, Peto R, Collins R, Li L, Chen Z; China Kadoorie Biobank Collaborative Group. Lipids, Lipoproteins, and Metabolites and Risk of Myocardial Infarction and Stroke. J Am Coll Cardiol. 2018 Feb 13;71(6):620-632.

26. 26. Hindy G, Engström G, Larsson SC, Traylor M, Markus HS, Melander O,Orho-Melander M; Stroke Genetics Network (SiGN). Role of Blood Lipids in the Development of Ischemic Stroke and its Subtypes: A Mendelian Randomization Study.Stroke. 2018 Apr;49(4):820-827.

27. 27.Keene D, Price C, Shun-Shin MJ, Francis DP. Effect on cardiovascular risk of high density lipoprotein targeted drug treatments niacin, fibrates, and CETP inhibitors: meta-analysis of 
randomised controlled trials including 117,411 patients. BMJ. 2014 Jul 18;349:g4379.

28. 28.Pikula A, Beiser AS, Wang J, Himali JJ, Kelly-Hayes M, Kase CS, Yang Q,Seshadri S, Wolf PA. Lipid and lipoprotein measurements and the risk of ischemic vascular events: Framingham Study. Neurology. 2015 Feb 3;84(5):472-9.

29. 29.AIM-HIGH Investigators, Boden WE, Probstfield JL, Anderson T, Chaitman BR, Desvignes-Nickens $P$, Koprowicz K, McBride R, Teo K, Weintraub W. Niacin in patients with low HDL cholesterol levels receiving intensive statin therapy. N Engl J Med. 2011 Dec 15;365(24):2255-67.

30. 30.Villines TC, Stanek EJ, Devine PJ, et al. The ARBITER 6-HALTS Trial (Arterial Biology for the Investigation of the Treatment Effects of Reducing Cholesterol 6-HDL and LDL Treatment Strategies in Atherosclerosis): final results and the impact of medication adherence,dose, and treatment duration. J Am Coll Cardiol 2010;55:2721-6.

31. 31.Qiu R, Gao Y, Hou D, Wang Y, Yu C, Wang W, Liu S, Gao C, Tong X, Wu J. Association between hsCRP Levels and the Outcomes of Patients with Small-Artery Occlusion. Front Aging Neurosci. 2016 Aug 9;8:191.

32. 32.Crisby M, Bronge L, Wahlund LO. Low levels of high density lipoprotein increase the severity of cerebral white matter changes: implications for prevention and treatment of cerebrovascular diseases. Curr Alzheimer Res. 2010 Sep;7(6):534-9.

33. 33.Rohatgi A, Khera A, Berry JD, Givens EG, Ayers CR, Wedin KE, Neeland IJ,Yuhanna IS, Rader DR, de Lemos JA, Shaul PW. HDL cholesterol efflux capacity and incident cardiovascular events. N Engl J Med. 2014 Dec 18;371(25):2383-93.

34. 34.Meng GL, Tan Y, Fang M, Yang HY, Liu XY, Zhao YX. Paradoxical Elevation of High Density Lipoprotein Cholesterol in Association with Lacunar-Type Cerebral Infarction. Med Sci Monit. 2015 Jun 29;21:1872-8.

35. 35.Lv P, Zhao M, Liu Y, Jin H, Cui W, Fan C, Teng Y, Zheng L, Huang Y.Apolipoprotein C-III in the highdensity lipoprotein proteome of cerebral lacunar infarction patients impairs its anti-inflammatory function. Int J Mol Med. 2018 Jan;41(1):61-68.

36. 36.Knottnerus IL, Ten Cate H, Lodder J, Kessels F, van Oostenbrugge RJ. Endothelial dysfunction in lacunar stroke: a systematic review. Cerebrovasc Dis. 2009;27(5):519-26.

\section{Tables}

Table 1 - Baseline demographics and clinical characteristics according to HDL groups 


\begin{tabular}{|c|c|c|c|c|c|}
\hline & \multicolumn{4}{|c|}{ Quartile of $\mathrm{HDL}, \mathrm{mmol} / \mathrm{L}$} & \multirow[b]{2}{*}{$\mathbf{P}$} \\
\hline & $\begin{array}{l}<0.92(n \\
=733)\end{array}$ & $\begin{array}{c}0.92 \text { to }<1.08 \\
(n=768)\end{array}$ & $\begin{array}{c}1.08 \text { to }<1.28 \\
(n=791)\end{array}$ & $\begin{array}{l}\geq 1.28(n \\
\quad=775)\end{array}$ & \\
\hline $\begin{array}{c}\text { Age, years (median } \\
\text { values) }\end{array}$ & $61.42 \pm 11.28$ & $62.39 \pm 11.26$ & $61.98 \pm 10.89$ & $61.95 \pm 10.87$ & 0.409 \\
\hline Male sex, $\mathrm{n}(\%) *$ & $542(73.9)$ & $511(66.5)$ & $528(66.8)$ & $553(71.4)$ & 0.003 \\
\hline \multicolumn{6}{|l|}{ Risk factors } \\
\hline Hypertension, n(\%) & $490(66.8)$ & $479(62.4)$ & $525(66.4)$ & $489(63.1)$ & 0.162 \\
\hline Diabetes, n(\%)* & $305(41.6)$ & $213(27.7)$ & $223(28.2)$ & $164(21.2)$ & $<0.001$ \\
\hline Smokers, $\mathrm{n}(\%) *$ & $305(41.6)$ & 297(38.7) & $302(38.2)$ & $267(34.5)$ & 0.040 \\
\hline $\begin{array}{c}\text { Alcohol drinkers, } \\
\mathrm{n}(\%)\end{array}$ & $120(16.4)$ & $116(15.1)$ & $126(15.9)$ & $125(16.1)$ & 0.915 \\
\hline Obesity, n(\%) & $54(7.4)$ & $48(6.3)$ & $53(6.7)$ & $37(4.8)$ & 0.194 \\
\hline \multicolumn{6}{|l|}{ Laboratory findings } \\
\hline $\begin{array}{c}\mathrm{TG}, \mathrm{mmol} / \mathrm{L} \text { (median } \\
\text { values)* }\end{array}$ & $2.09 \pm 1.48$ & $1.76 \pm 1.00$ & $1.58 \pm 0.88$ & $1.46 \pm 0.96$ & $<0.001$ \\
\hline $\begin{array}{c}\mathrm{TC}, \mathrm{mmol} / \mathrm{L}(\text { median } \\
\text { values)* }\end{array}$ & $4.59 \pm 1.82$ & $4.87 \pm 0.95$ & $5.05 \pm 0.98$ & $5.39 \pm 1.06$ & $<0.001$ \\
\hline $\begin{array}{c}\text { HDL-C, } \\
\text { mmol/L(median } \\
\text { values)* }\end{array}$ & $0.79 \pm 0.97$ & $0.99 \pm 0.45$ & $1.17 \pm 0.56$ & $1.53 \pm 0.30$ & $<0.001$ \\
\hline $\begin{array}{c}\text { LDL-C, } \\
\text { mmol/L(median } \\
\text { values)* }\end{array}$ & $2.68 \pm 0.79$ & $2.90 \pm 0.78$ & $2.96 \pm 0.79$ & $3.02 \pm 0.85$ & $<0.001$ \\
\hline NIHSS, n(\%) & & & & & 0.526 \\
\hline $0-6$ & $538(73.4)$ & $548(71.4)$ & $570(72.1)$ & $577(74.5)$ & \\
\hline $7-14$ & $195(26.6)$ & $220(28.6)$ & $221(27.9)$ & $198(25.5)$ & \\
\hline
\end{tabular}

* Indicates $\mathrm{P}<0.05$ when comparing between four groups. TC, total cholesterol; TG, triglyceride; HDL, highdensity lipoprotein cholesterol; LDL-C, low-density lipoprotein cholesterol;NIHSS, National Institute of Health stroke scale

Table 2 - Comparison of the risk factors between different groups classified by outcomes 


\begin{tabular}{|c|c|c|c|c|c|c|}
\hline & $\mathrm{mRS} \leq 2$ & $\mathrm{mRS} \geq 3$ & $\begin{array}{c}P \\
\text { Value }\end{array}$ & $\mathrm{mRS} \leq 2$ & $\begin{array}{l}\text { Composite } \\
\text { endpoints }\end{array}$ & $\begin{array}{c}P \\
\text { Value }\end{array}$ \\
\hline & $(n=2284)$ & $(n=222)$ & & $(n=2284)$ & $(n=783)$ & \\
\hline $\begin{array}{c}\text { Age, years (median } \\
\text { values) }\end{array}$ & $60.87 \pm 10.82$ & $64.23 \pm 11.00$ & $<0.001$ & $60.87 \pm 10.82$ & $65.08 \pm 11.23$ & $<0.001$ \\
\hline Male sex, $n(\%)$ & 1596(69.9) & $142(64.0)$ & 0.068 & $1596 \square 69.9 \square$ & $538 \square 68.7 \square$ & 0.540 \\
\hline Hypertension, n(\%) & $1482(64.9)$ & $135(60.8)$ & 0.226 & $1482 \square 64.9 \square$ & $501 \square 64.0 \square$ & 0.649 \\
\hline Diabetes, n(\%) & $660(28.9)$ & $74(33.3)$ & 0.166 & $660 \square 28.9 \square$ & $245 \square 31.3 \square$ & 0.205 \\
\hline Smokers, n(\%) & 868(38.0) & $78(35.1)$ & 0.400 & 868ロ38.0ロ & 303₫38.7凹 & 0.730 \\
\hline Alcohol drinkers, $n(\%)$ & $366(16.0)$ & $34(15.3)$ & 0.783 & $366 \square 16.0 \square$ & $121 \square 15.5 \square$ & 0.706 \\
\hline Obesity, n(\%) & $151(6.6)$ & $13(5.9)$ & 0.664 & $151 \square 6.6 \square$ & $41 \square 5.2 \square$ & 0.171 \\
\hline HDL, $n(\%)$ & & & 0.006 & & & 0.037 \\
\hline$<0.92$ & $527(23.1)$ & $69(31.1)$ & & $527 \square 23.1 \square$ & $206 \square 26.3 \square$ & \\
\hline$\geq 0.92$ & $558(24.4)$ & $60(27.0)$ & & $558 \square 24.4 \square$ & $210 \square 26.8 \square$ & \\
\hline$\geq 1.08$ & $597(26.1)$ & $54(24.3)$ & & 597ロ26.1凹 & $194 \llbracket 24.8 \square$ & \\
\hline$\geq 1.28$ & $602(26.4)$ & $39(17.6)$ & & $602 \llbracket 26.4 \square$ & $173 \llbracket 22.1 \square$ & \\
\hline NIHSS, n(\%) & & & $<0.001$ & & & $<0.001$ \\
\hline $0-6$ & 1795(78.6) & $75(33.8)$ & & $1795 \square 78.6 \square$ & $438 \square 55.9 \square$ & \\
\hline$\geq 7$ & $489(21.4)$ & $147(66.2)$ & & $489 \square 21.4 \square$ & $345 \square 44.1 \square$ & \\
\hline
\end{tabular}

mRS: modified Rankin scale; NIHSS: National Institute of Health stroke scale;HDL, high-density lipoprotein cholesterol;

Table 3 - Multivariate logistical regression analyses of HDL groups and the outcome variables

\begin{tabular}{|c|c|c|c|c|}
\hline & \multicolumn{2}{|c|}{ Primary outcome } & \multicolumn{2}{|c|}{ Secondary outcome } \\
\hline & OR ( $95 \% \mathrm{CI}$ ) & $P$ Value & OR ( $95 \% \mathrm{CI}$ ) & $P$ Value \\
\hline Age & 1.026(1.012-1.039) & $<0.001$ & $1.034 \square 1.026-1.042 \square$ & $<0.001$ \\
\hline \multicolumn{5}{|l|}{ HDL } \\
\hline$<0.92$ & index & index & index & index \\
\hline$\geq 0.92$ & $0.706(0.478-1.042)$ & 0.079 & $0.901 \llbracket 0.712-1.140 \square$ & 0.386 \\
\hline$\geq 1.08$ & $0.587(0.394-0.873)$ & 0.009 & 0.788ロ0.621-0.999ロ & 0.049 \\
\hline$\geq 1.28$ & $0.448(0.291-0.688)$ & $<0.001$ & 0.713ロ0.560-0.909ロ & 0.006 \\
\hline \multicolumn{5}{|l|}{ NIHSS } \\
\hline $0-6$ & index & index & index & index \\
\hline$\geq 7$ & 7.165(5.314-9.660) & $<0.001$ & 2.796ロ2.345-3.333ロ & $<0.001$ \\
\hline
\end{tabular}


mRS: modified Rankin scale; NIHSS: National Institute of Health stroke scale;HDL, high-density lipoprotein cholesterol;

Table 4 - Multivariate logistical regression analyses of HDL groups classified by age and outcomes 


\begin{tabular}{|c|c|c|c|c|c|c|c|}
\hline & & OR(95\%CI) & $\begin{array}{c}P \\
\text { Value }\end{array}$ & OR(95\%CI) & $\begin{array}{c}P \\
\text { Value } \\
\end{array}$ & OR(95\%CI) & $\begin{array}{c}P \\
\text { Value } \\
\end{array}$ \\
\hline & & \multicolumn{2}{|c|}{$<45(n=140)$} & \multicolumn{2}{|c|}{45 to $<75(n=2054)$} & \multicolumn{2}{|c|}{$\geq 75(n=312)$} \\
\hline \multirow{15}{*}{$\begin{array}{l}\text { Primary } \\
\text { outcome }\end{array}$} & $\mathrm{HDL}$ & & & \multirow{2}{*}{\multicolumn{2}{|c|}{ index }} & \multirow{2}{*}{\multicolumn{2}{|c|}{ index }} \\
\hline & $<$ & index & & & & & \\
\hline & \multicolumn{7}{|l|}{0.92} \\
\hline & \multirow[b]{2}{*}{0.92} & $0.585(0.049-$ & 0.672 & $0.650(0.411-$ & 0.064 & 0.977(0.434- & 0.956 \\
\hline & & $6.971)$ & & 1.026) & & $2.202)$ & \\
\hline & \multirow[b]{2}{*}{1.08} & $2.788(0.404-$ & 0.298 & $0.615(0.393-$ & 0.033 & $0.380(0.145-$ & 0.049 \\
\hline & & 19.243) & & $0.963)$ & & $0.998)$ & \\
\hline & \multirow[b]{2}{*}{1.28} & $0.000(0.000-)$ & 0.998 & $0.452(0.278-$ & 0.001 & 0.496(0.188- & 0.156 \\
\hline & & & & $0.734)$ & & 1.307) & \\
\hline & \multicolumn{7}{|l|}{ NIHSS } \\
\hline & & \multicolumn{2}{|l|}{ index } & \multicolumn{2}{|l|}{ index } & \multicolumn{2}{|l|}{ index } \\
\hline & \multicolumn{7}{|l|}{$0-6$} \\
\hline & \multirow[b]{2}{*}{$\geq 7$} & $4.573 \square 0.810-$ & 0.085 & 8.501(6.010- & $<0.001$ & $3.937(2.060-$ & $<0.001$ \\
\hline & & 25.832) & & 12.024) & & 7.524) & \\
\hline & & \multicolumn{2}{|c|}{$<45(n=156)$} & \multicolumn{2}{|c|}{45 to $<75(n=2462)$} & \multicolumn{2}{|c|}{$\geq 75(n=449)$} \\
\hline \multirow{16}{*}{$\begin{array}{l}\text { Secondary } \\
\text { outcome }\end{array}$} & \multirow[t]{2}{*}{ Age } & \multirow{3}{*}{$\begin{array}{c}0.984 \square 0.889- \\
1.089 \square\end{array}$} & \multirow[t]{2}{*}{0.756} & \multirow{3}{*}{$\begin{array}{c}1.026(1.013- \\
1.038)\end{array}$} & \multirow[t]{3}{*}{$<0.001$} & \multirow{3}{*}{$\begin{array}{c}1.056(1.001- \\
1.115)\end{array}$} & \multirow[t]{3}{*}{0.046} \\
\hline & & & & & & & \\
\hline & \multicolumn{2}{|l|}{ HDL } & & & & & \\
\hline & $<$ & \multicolumn{2}{|l|}{ index } & index & & index & \\
\hline & 0.92 & & & & & & \\
\hline & $\geq$ & $0.742(0.189-$ & 0.668 & 0.868(0.663- & 0.305 & 1.091(0.639- & 0.750 \\
\hline & 0.92 & 2.911) & & 1.137) & & 1.863) & \\
\hline & $\geq$ & $2.664(0.803-$ & 0.109 & 0.788(0.602- & 0.081 & 0.639(0.365- & 0.118 \\
\hline & 1.08 & 8.844) & & 1.030) & & 1.119) & \\
\hline & $\geq$ & $0.691(0.156-$ & 0.627 & $0.684(0.520-$ & 0.007 & $0.830(0.473-$ & 0.516 \\
\hline & 1.28 & 3.065) & & 0.901) & & 1.456) & \\
\hline & NIHSS & & & & & & \\
\hline & & index & & index & & index & \\
\hline & $0-6$ & & & & & & \\
\hline & & 2.706(0.983- & 0.054 & 2.995(2.451- & $<0.001$ & 2.119(1.424- & $<0.001$ \\
\hline & $\geq 7$ & 7.448) & & 3.659) & & 3.155) & \\
\hline
\end{tabular}

mRS: modified Rankin scale; NIHSS: National Institute of Health stroke scale;HDL, high-density lipoprotein cholesterol; 


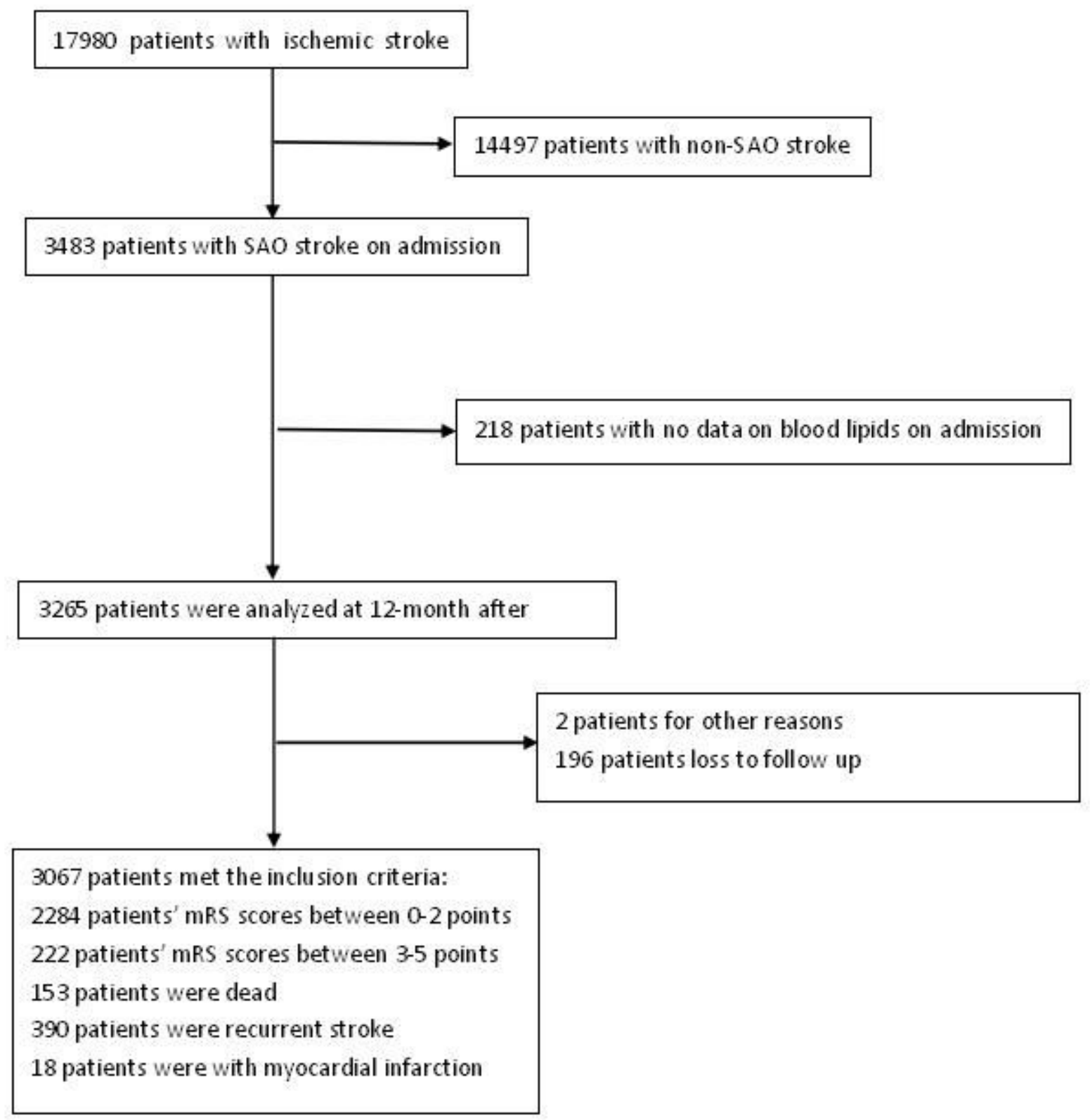

Fig. 1 Flow chart of patient selection

$S A O$ : small-artery occlusion

\section{Figure 1}

Flowchart for patient selection. 